\title{
CORROSION PROPERTIES OF VARIOUS COPPER PIPES JOINTS
}

\begin{abstract}
The paper presents the experimental results of various $C$ u pipes joint corrosion behavior. Joining of copper pipes used for liquid media transport can be made as demountable and fixed joints. The object is to study corrosion resistance of the joints created by soft soldering, hard soldering and fitting. Corrosion properties were investigated by long-term experiment in two identical experimental devices in stagnant and flowing conditions. The experimental environment was water solution of the $3 \% \mathrm{NaCl}$, temperature was kept $20^{\circ} \mathrm{C}$ for 16 hours and 8 hours $80^{\circ} \mathrm{C}$ per day. In one of the devices for 8 hours the experimental solution was flowing by the input speed $0.27 \mathrm{~m} \cdot \mathrm{s}^{-1}$. In the second one no flow was applied. Evaluation of the joints corrosion attacks was performed visually, by light and scanning electron microscopy.
\end{abstract}

Keywords: Copper pipes, joints, corrosion, corrosion products.

\section{Introduction}

Copper pipes are mostly used for the distribution of gas and liquid media in a variety of industries. They are used for their excellent corrosion properties and long life [1 - 6]. Due to the differences in device geometry of distribution lines, copper pipes must be bent in certain locations or linked with another circuit. At present mainly three types of joints are used to connect copper pipes. They are the permanent joints made by soft or hard soldering and the demountable joints formed by pressing plastic ring which creates a joint between the copper pipes fixed closed connection (the fitting) [7 and 8]. The joints in copper pipes comprise inhomogeneities which affect, e.g. media flow change, character and sedimentation of corrosion products and thus the degradation process. The main aim of the work was to monitor the synergetic effect of mechanical and chemical stress on corrosion-erosion behavior of the copper pipes joints. The degradation was assessed visually, by light and scanning electron microscopy.

\section{Experiments}

Corrosion behavior of the copper pipes joints was verified by a long-term experiment lasting 11 months. The experimental conditions were chosen to simulate the ones in real distribution. During a day boundary conditions by increasing the temperature and flow of the working medium were set because even their shortterm activity can influence the course of corrosion processes.

2.1 Equipment and conditions
For the experiment two identical devices of technical copper $(99.5 \% \pm 0.5 \% \mathrm{Cu})$ with two types of permanent joints (soft and hard soldering) and one type of demountable molded joint were made. In Fig. 1 the experimental equipment with the marked localities of joints is shown.

Joints were formed under the following conditions:

1. Soft soldering (Fig. 1, area 2, 5, 11) was performed according to DIN 1707 solder L- SnCu3 (DIN EN 29453, S-Sn97Cu3) at $230^{\circ} \mathrm{C}$.

2. Hard soldering (Fig. 1, area 4, 6) was performed according to DIN 8513 (EN 1044) using flux and solder CP 203 and L $\mathrm{CuP} 6$ at $730^{\circ} \mathrm{C}$.

3. The demountable fitting was created by pressing of $\mathrm{Cu}$ pipes with the polymers (Fig. 1, area 3, 9).

Experimental conditions were chosen to simulate operating conditions in practice. The first experimetnal equipment was filled with the $3 \%$ sodium chlorid solution, 16 hours exposed at $20 \pm$ $2{ }^{\circ} \mathrm{C}$ without flow of the solution, 8 hours at $80{ }^{\circ} \mathrm{C}$ with flow of the solution at the input rate of $0.27 \mathrm{~m} . \mathrm{s}^{-1}$, caused by an electric motor and observed by a flowmeter. To verify the flow properties in the experimental system the CFD method was used. The method allows quantifying flows and modeling of temperature and flow fields based on Computational Fluid Dynamics - finite volume method [9-10]. The second experimental equipment was exposed in the same condition but no flow was applied [11 - 13].

\footnotetext{
* ${ }^{1}$ Tatiana Liptakova, ${ }^{1}$ Monika Halamova, ${ }^{2}$ Ayman Alaskari, ${ }^{1}$ Martin Lovisek, ${ }^{3}$ Maxim Puchnin

${ }^{1}$ Department of Materials Engineering, Faculty of Mechanical Engineering, University of Zilina, Slovakia

${ }^{2}$ Department of Mechanical Production Technology, College of Technological Studies, Shuwaikh, Kuwait

${ }^{3}$ Department of Materials Engineering, Faculty of Mechanical Engineering, Czech Technical University in Prague, Czech Republic

E-mail: tatiana.liptakova@fstroj.uniza.sk
} 

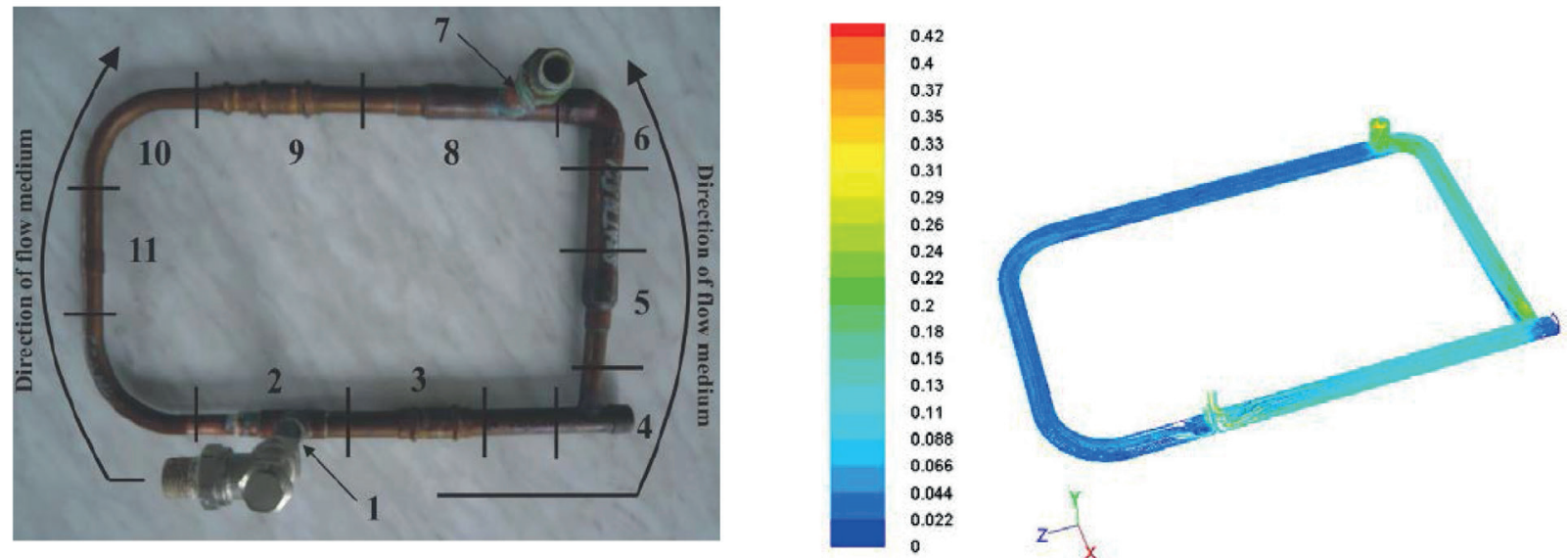

Fig. 1 Experimental equipment and flow conditions

\section{Results}

After 11 months of exposure the samples were taken off, incised to be possible to assess corrosion attack of the monitored joints in stagnant and flow conditions. Assessment of the different joints after exposure was made visually, by light and scan electron microscopy.

\subsection{Hard soldering joints}

Corrosion attack in the localities of the joint is the same as the one of $\mathrm{Cu}$ pipes. In stagnant conditions the corrosion products were black-grey. According to the Pourbaix diagram corrosion products in aqua environment are (in the potential range from $-0.15 \mathrm{~V}$ to $+0.521 \mathrm{~V})$ formed by $\mathrm{CuO}\left(\mathrm{Cu}^{2+}\right)$ which are black and complex compounds $\mathrm{CuCl}_{2} 3 \mathrm{Cu}(\mathrm{OH})_{3}$. Higher temperature $\left(80^{\circ} \mathrm{C}\right)$ does not influence the character of corrosion products but their formation is shifted to more acid area (lower value of $\mathrm{pH}$ ). When the solution is flowing, the character of corrosion products is changed by hydrolysis to greenish color (presence of $\mathrm{CuCl}$ and $\mathrm{CuCl}^{(+a)}$ ) as shown in Fig. 2. These corrosion products have pure adherence and by flow they are torn off from the metal surface especially on the top of the pipe. No differences of corrosion product character between $\mathrm{Cu}$ pipe and the locality of hard soldering joints are observed. In Fig. $2 \mathrm{~b}$, the start of intergranular corrosion on the joint and $\mathrm{Cu}$ pipe boundary was observed. In flow conditions the surface roughness

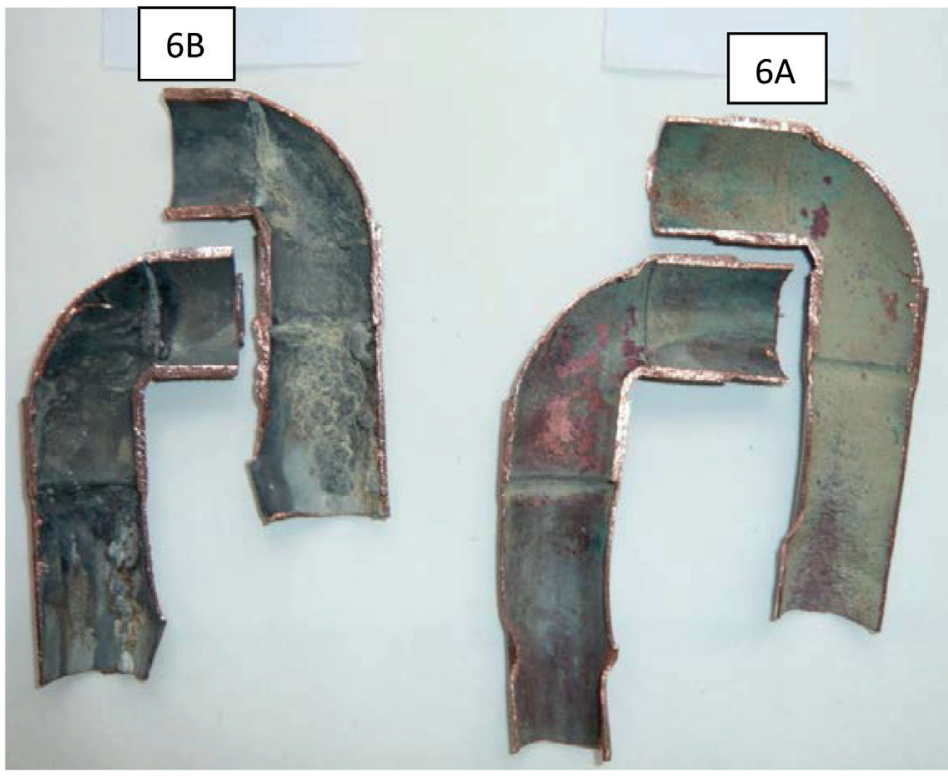

a)

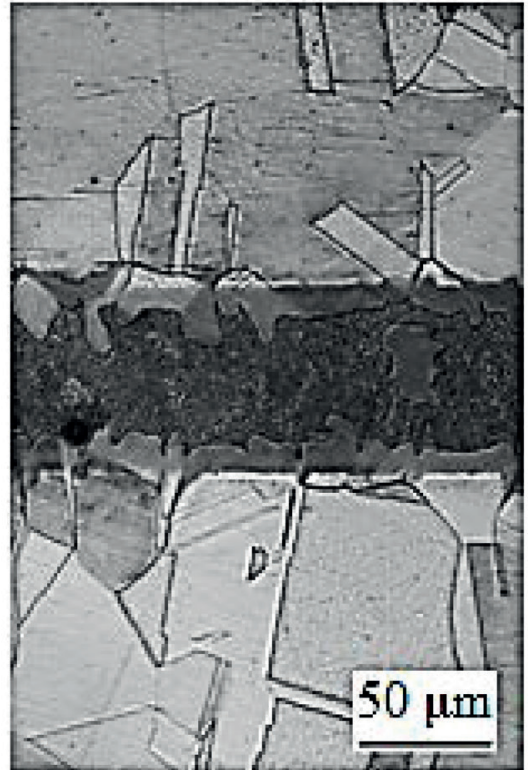

b)

Fig. 2 Character of corrosion in the locality with hard soldering joints

$6 B-$ no flow and 6 A flow conditions a), and detail joint microstructureb) 


\section{caMMNICOIIONS}

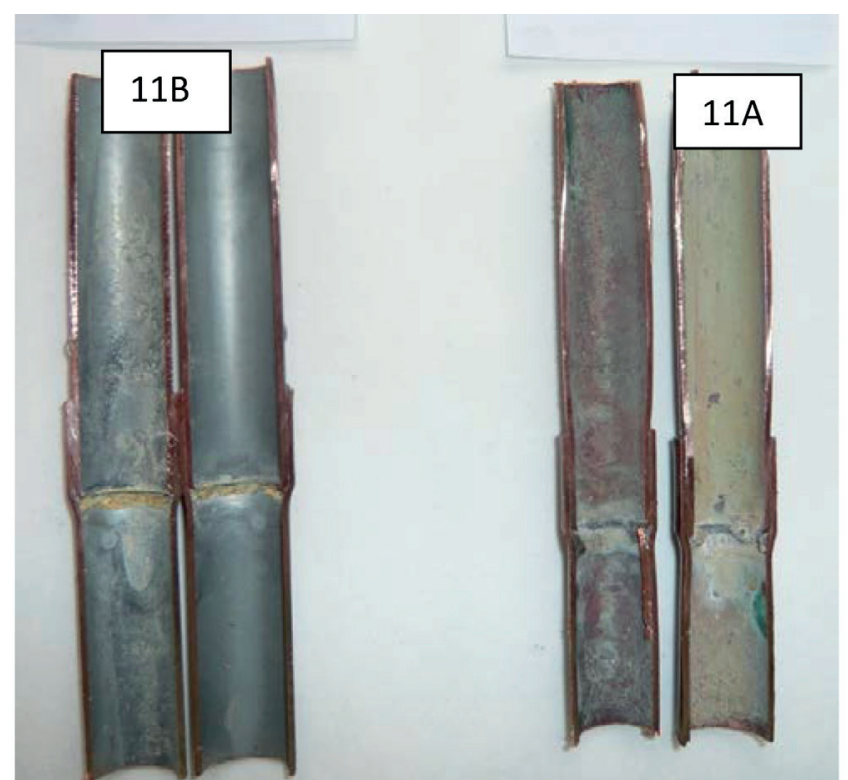

a)

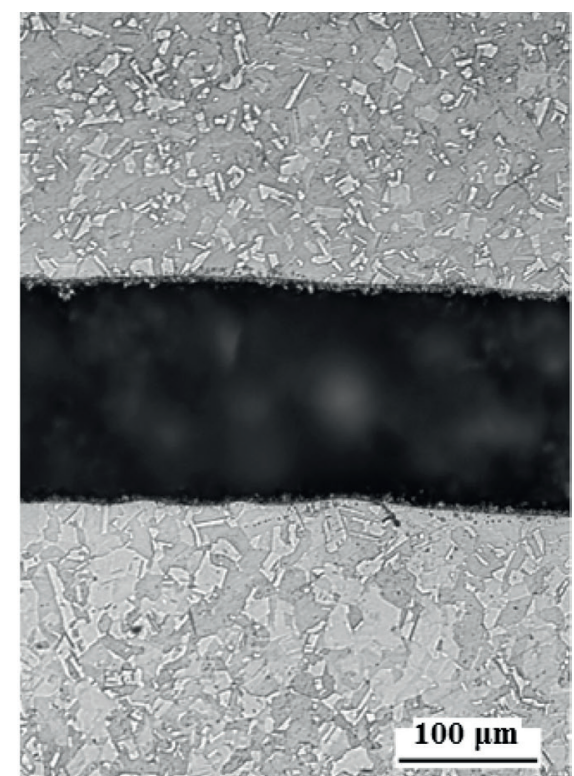

b)

Fig. 3 Character of corrosion in the locality with hard soldering joints

$6 B$ - no flow and $6 A$ flow conditions a), and detailed joint microstructureb)

of the joint can change the flow character and increase its effect on damage of $\mathrm{Cu}$ pipe system by corrosion-erosion (Fig. 2a, 6A).

\subsection{Soft soldering joints}

The joints created by soft soldering differ from $\mathrm{Cu}$ pipe by chemical composition of solder ( $97 \%$ tin Sn). Metallography

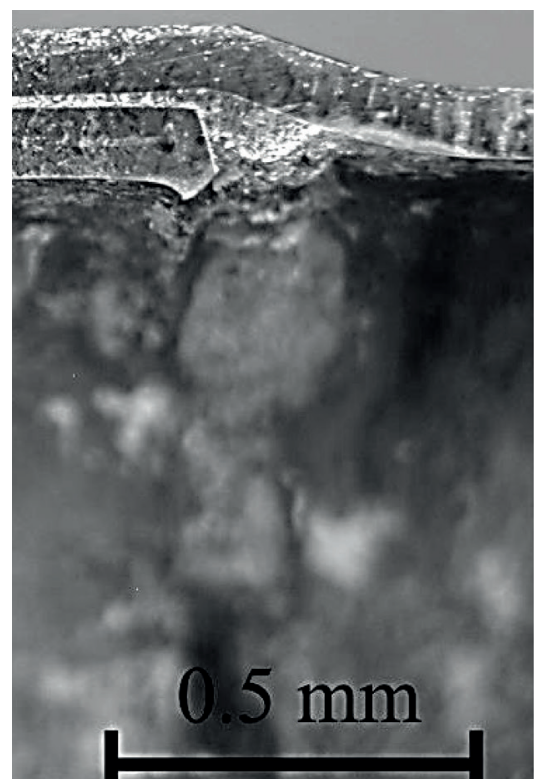

a)

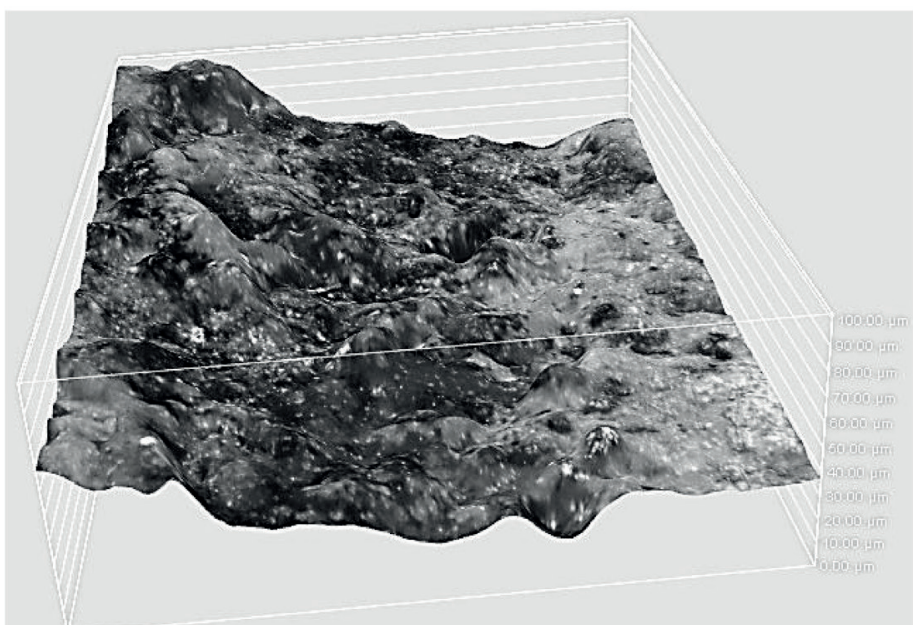

b) of the soldering joint and corrosion attack in flow and no flow conditions is shown in Fig. 3a.

The $\mathrm{Sn}$ solder has quite good corrosion resistance. In corrosion environment (scale $\mathrm{pH} 3.5$ - 9) the stable oxides $\mathrm{SnO}$ and $\mathrm{SnO}_{2}$ are created on the surface and feature protection character. The $\mathrm{Sn}$ solder creates with $\mathrm{Cu}$ pipe a local galvanic sell in the electrolyte and $\mathrm{Sn}$ behaves as an anode. After the experiment the local corrosion was determined in the Sn joints in stagnant and flowing conditions. Local corrosion was evoked by

Fig. 4 Corrosion pits on the Sn joint a) and 3-dimensional surface of Sn with visible pits b) 


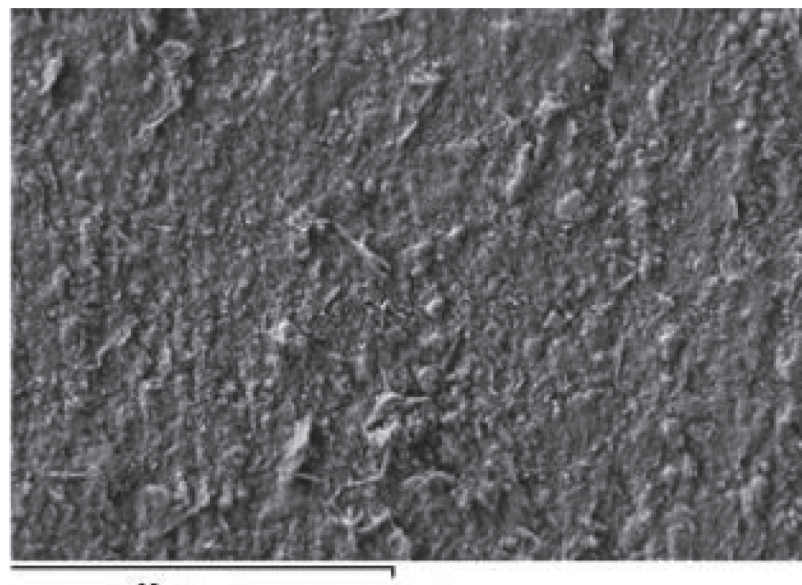

$60 \mu \mathrm{m}$

a)

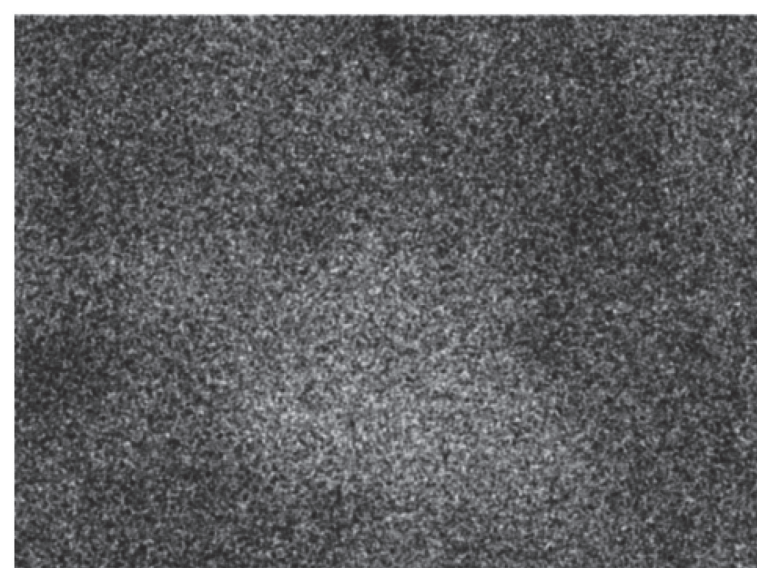

Sn La1

Fig 5. Corrosion products on Cu pipe near Sn joint in stagnant conditions a) and the map of Sn distribution on the surface b)

chloride ions presentation and influenced by higher temperature. Metallography of corrosion attack of the Sn solder and its morphology are in Fig. 4 (a, b).

Intensive corrosion of $\mathrm{Sn}$ solder was confirmed by EDX analysis of its corrosion products. The Sn corrosion products diffuse to the electrolyte and they are accumulated in the bottom of $\mathrm{Cu}$ pipe. In Fig. 5 the character of corrosion products made by SEM near Sn joint can be seen (a) and a map of Sn distribution (light points) in stagnant solution (b). In Fig 6 the character of corrosion products is compared with Sn distribution from identical place but in flowing solution. Sn corrosion products are more scattered by flow influence and mixed with $\mathrm{Cu}$ corrosion products. It is proved by the EDX analysis of corrosion products in no flowing and flowing conditions in the identical places.
In Table 1 chemical composition of corrosion products in stagnant and flow conditions is specified.

Chemical composition of corrosion products in stagnant and flow condition

Table 1

\begin{tabular}{|c|c|c|c|c|}
\hline Element & \multicolumn{2}{|c|}{ Stagnant conditions } & \multicolumn{2}{c|}{ Flow conditions } \\
\hline & Weight \% & Atom. \% & Weight \% & Atom. \% \\
\hline $\mathbf{O}$ & 8.7 & 31.65 & 65.63 & 88.87 \\
\hline $\mathbf{C l}$ & 0.56 & 0.91 & 1.82 & 1.11 \\
\hline $\mathbf{C u}$ & 57.67 & 49.85 & 25.74 & 8.78 \\
\hline $\mathbf{S n}$ & 36.03 & 17.59 & 6.8 & 1.24 \\
\hline
\end{tabular}

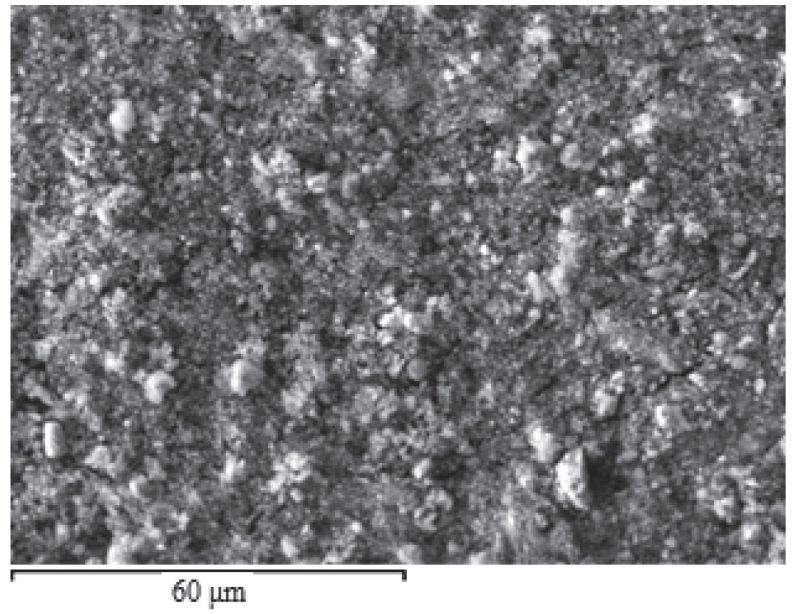

a)

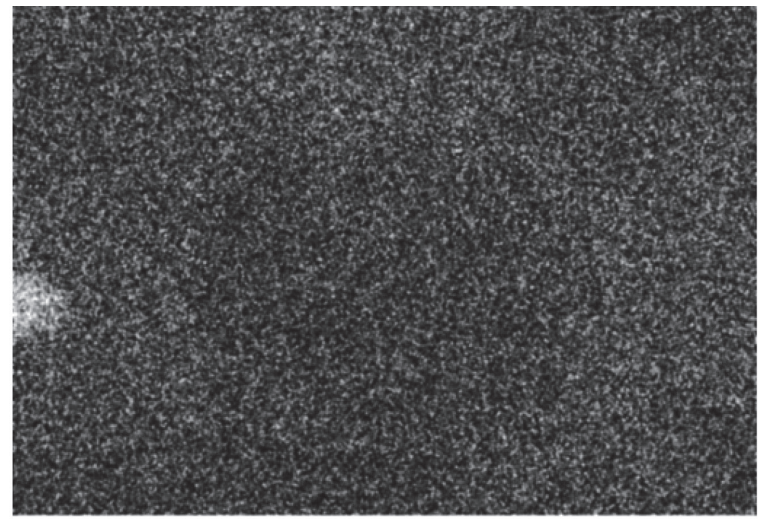

Sin La1

Fig 6. Corrosion products on Cu pipe near Sn joint in flow conditions a) and the map of Sn distribution on the surface b) 


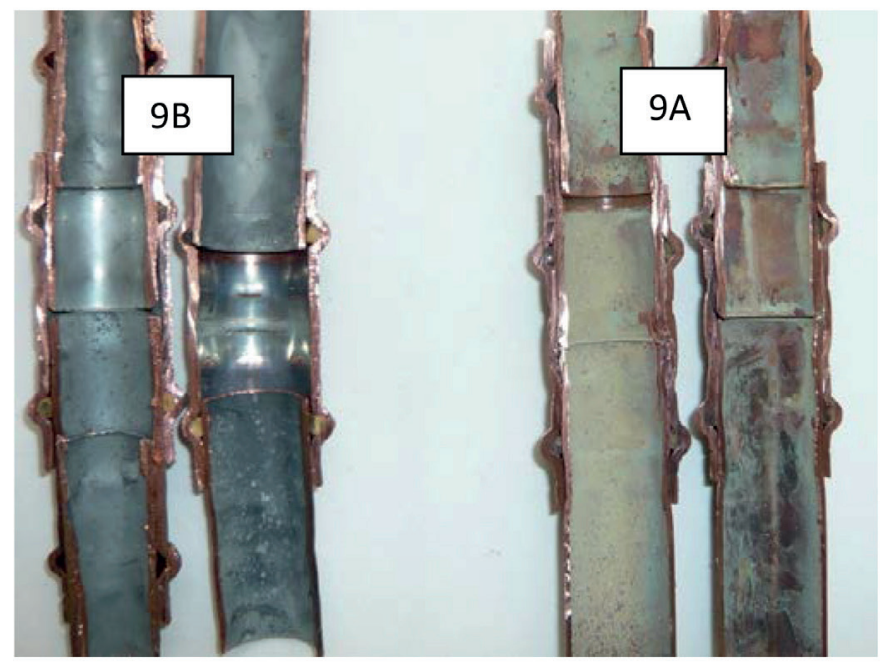

a)

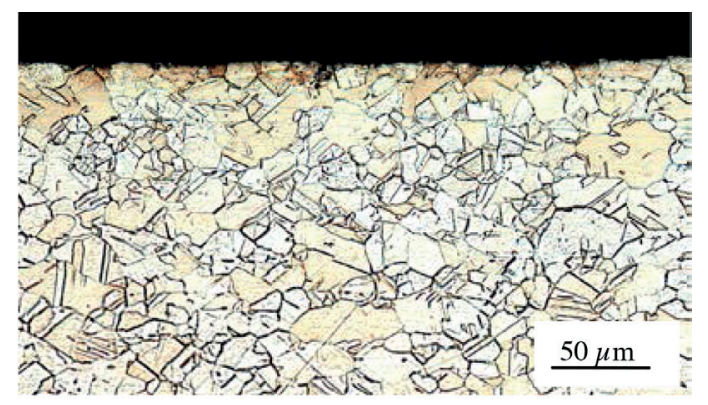

B

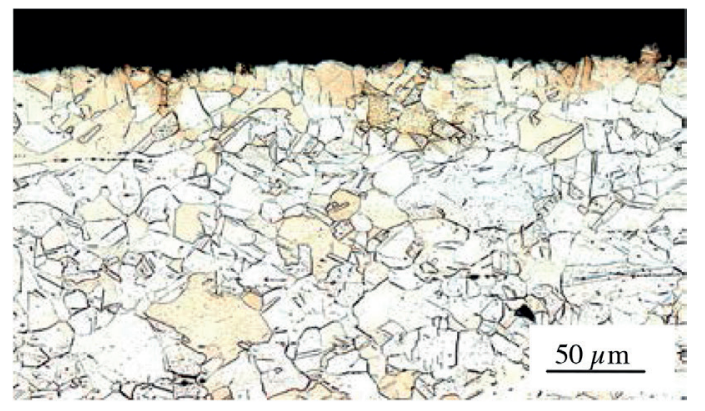

A

b)

Fig. 7 Localities of fitting in stagnant $9 B$ and flow conditions $9 A$ a) and microstructure of corrosion attack (b)

\subsection{Fitting}

The demountable joint - fitting was constructed at normal room temperature by pressing of $\mathrm{Cu}$ pipes with polymer. In this way a very good sealing joint was created without any intermediate film. As it can be seen in Fig. 7a, fitting did not affect character of the $\mathrm{Cu}$ corrosion products in stagnant and flow conditions. In the joint locality of $\mathrm{Cu}$ pipes no corrosion attack was observed. In moving solution only joint protrusions can slightly change the linear flow. In Fig. $7 \mathrm{~b}$ the character and intensity of $\mathrm{Cu}$ pipe corrosion in stagnant (B) and flow conditions (A) are presented.

\section{Conclusions}

With regard on the obtained results share can be stated:

\section{Conclusions}

- Joints molded by hard soldering were not attacked more intensively than basic material - technical copper. The joint forms in the pipe system crevices and stagnation of operating medium in these crevices creates conditions for corrosion attack. Geometry of crevices can also cause changes in lamellar flowing of operating solution and so it can increase its mechanical effect. The loss of stability of protective cuprous oxide layer due to the hydrolysis and corrosion- erosion impact is the main cause of faster damage of copper in flow environment.

- Tin joints are attacked by pitting corrosion in medium containing chlorides. The intensity of corrosion damage is not very dangerous for actual dimensions of joint and their stability is not endangered. The empty places originated by inappropriate soldering are more dangerous for safety of the joint. The solid particles of the Sn corrosion products increase the erosion effect in flow conditions.

- Demountable joints formed by pressing plastic rings with polymer material tighten excellently even in aggressive $3 \%$ $\mathrm{NaCl}$ solution in stagnant and flowing conditions too. The joints create only a little mechanical barrier for flowing medium in $\mathrm{Cu}$ pipe system. The hidden areas in the joint locality were in untouched state without any sign of corrosion or in-leak between joined pipes.

\section{Acknowledgements}

The research was supported by European regional development fund and Slovak state budget by the project "Research center of University of Zilina”, ITMS 26220220183. The authors thank for their support. 


\section{References}

[1] SRIVASTAVA, A., BALASUBRAMANIAM, R.: Microstructural Characterization of Copper Corrosion in Aqueous and Soil Environments, Materials Characterization, vol. 55, No. 2, August 2005, 127-135.

[2] JANECEK, M., HADZIMA, B., HELLMIG, R.J., ESTRIN, Y.: The Influence of Microstructure on the Corrosion Properties of Cu Polycrystals Prepared by ECAP. Kovove mater., 43 (4), 2005, 258 p.

[3] HADZIMA, B., JANECEK, M., KUTNYAKOVA, Y., HELLMIG, R. J., ESTRIN, Y.: Microstructure and Corrosion behaviour of Ultrafine-grained Copper, Mater. Sci. Forum, vols. 503-504, 2006, 883-888.

[4] NAVRATILOVA, L., KUNZ, L., NOVY, F., MINTACH, R.: Development of Cyclic Slip Bands in UFG Copper in Gigacycle Fatigue, Acta Metallurgica Slovaca, vol. 19, No. 2, 2013, 88-93.

[5] MERKEL, T. H., GROSS, H. J., WERNER, W., DAHLKE, T., REICHERTER, S., BEUCHLE, G., EBERLE, S. H.: Water Research, 36, 2001, 1547-1555.

[6] SANDBERG, J., ODNEVALL WALLINDER, I., LEYGRAF, C., LE BOZEC, N.: Corr. Sci., 48, 2006, 4316-4338.

[7] LEZDIK, V., SOBOTA, M., BEZAK, J.: Welding in Gas Industry (in Slovak), EDIS: University of Zilina, 2001.

[8] BOSCO, N. S., ZOK, F.V.: Strength of Joints Produced by Transient Liquid Phase Bonding in the Cu-Sn System, Acta Materialia 53, 2005, 2019-2027.

[9] LENHARD, R., JAKUBSKY, M., MALCHO, M., JANDACKA, J.: Analysis of Transmission Phenomena in Low-potential Heat Transport by Heat Pipes in the Deep-borehole Simulator, Communications - Scientific Letters of the University of Zilina, vol. 14, No. 3, 2012, 10-16.

[10] KAPJOR, A., MALCHO, M., JANDACKA, J., HUZVAR, J., GRESAK, T.: Optimization of Construction Parameters of a Flow Convector, Communications - Scientific Letters of the University of Zilina, vol. 14, No. 4a, 2012, 36-41.

[11] BABOIAN, R. et al.: Corrosion Test and Standards: Application and Interpretation. ASTM Manual Series, Philadelphia: PA 19103, 1995.

[12] ASM Handbook: Corrosion, vol. 13, The Material Information Society, 4th Printing, 1992.

[13] LIPTAKOVA, T., FAJNOR, P., DODEK, A.: Evaluation of the Flow Accelerated Corrosion of Copper Pipes, Materials Engineering = Materialove inzinierstvo, vol. 17, No. 4, 2010. 